\title{
The effectiveness of the antegrade reamed technique: the experience and complications from 415 traumatic femoral shaft fractures
}

\author{
Efthimios J. Karadimas • George Papadimitriou • \\ Gerasimos Theodoratos • Anastasios Papanikolaou • \\ John Maris
}

Received: 10 November 2008 / Accepted: 8 November 2009/Published online: 21 November 2009

(C) Springer-Verlag 2009

\begin{abstract}
This retrospective study presents the experience gained through use of reamed femoral nails and reports results and respective complications. This study included 415 femur fractures (312 men and 101 women with a mean age of 27.8 years) that were treated from 1993 to 2004 . The fractures were classified according to $\mathrm{AO}$, and 74 open fractures were included and typed according to the Gustilo classification. Dynamic nailing was performed for nearly all type A fractures and static nailing for types B and C. After a mean follow-up of 1.5 years, union rate was $97.8 \%$. The complications were: 9 non-unions, 14 delayed-unions, 4 torsional malunions, 6 limb length discrepancies (shortening) and 30 nerve pareses due to traction. Deep venous thrombosis (DVT) occurred below the knee in 4 patients, while there were recorded 3 pulmonary and 2 fat embolisms, 1 superficial and 1 deep infection. There were 28 broken screws identified postoperatively. Logistic regression analysis revealed that type $\mathrm{B}$ and $\mathrm{C}$ were associated with increased risk of complications, with respective odds ratios of $3.1(95 \% \mathrm{CI}=1.3-7.2, P=0.011)$ and 4.3
\end{abstract}

\footnotetext{
E. J. Karadimas - G. Papadimitriou - G. Theodoratos . A. Papanikolaou $\cdot$ J. Maris

Orthopaedic Department, Hellenic Red Cross Hospital of Athens, 1st Erythrou stavrou, 11526 Athens, Greece e-mail: gpapadimitriou@gmail.com

G. Theodoratos

e-mail: g.theodoratos@gmail.com

A. Papanikolaou

e-mail:pkorkol@cc.uoa.gr

J. Maris

e-mail: jsmaris@otenet.gr

E. J. Karadimas $(\bowtie)$

10, Timoleontos. Vassou str, 11521 Athens, Greece

e-mail: eikaradimas@yahoo.gr
}

(95\% CI $=1.8-10.3, P=0.001)$ when compared to type A patterns. All patients returned to their activities in a mean time of 10 months. Intramedullary nailing is still the treatment of choice for femoral shaft fractures, but knowledge of potential complications and their association with certain fracture patterns is needed.

Keywords Fracture fixation - Intramedullary · Femoral fractures · Osteosynthesis .

Post-operative complications

\section{Introduction}

The treatment of femoral shaft fractures was revolutionised by Küntscher [1], who was the first to introduce the intramedullary nailing concept. The initial indications were limited to transverse diaphyseal femoral fractures but such advantages as early mobilisation, shorter hospitalisation and shorter morbidity popularised wider use of femoral nails $[2,3]$. Some complications such as infections, non-unions, pseudoarthrosis and limb shortening were observed. Improvements in nail design and manufacture as well as surgical technique, with the use of a fracture table and X-ray image intensifier, further broadened the use of femoral nails but it was the introduction of an interlocking capability in the mid-1970s that expanded the scope of indications to included comminuted fractures and fractures of the proximal and distal thirds $[4,5]$. These changes increased union rate and, as a result, intramedullary nails have become the preferred treatment for almost all diaphyseal femoral fractures [6-8].

Surgeons have been faced with several issues, in particular which fracture types should be treated ideally with intramedullary nails, if all fractures should have reamed 
nails and if symptoms of pulmonary distress are a contraindication to nail fixation [9-13]. The purpose of this retrospective study is to present our experience and report the results and complications in the treatment of 415 femoral shaft fractures using reamed interlocked intramedullary nails.

\section{Patients and methods}

In the interval from June 1993 to December 2004, 413 patients (415 fractures) were admitted with acute diaphyseal femoral fractures $(2.5 \mathrm{~cm}$ from the lesser trochanter and approximately $10 \mathrm{~cm}$ from the knee joint). Fractures caused by high-energy trauma, falls, and direct impact were included. Pathologic fractures and those in which intramedullary nailing was used as a revision technique to previous internal fixation or for arthrodesis were excluded. Also excluded (with the exception of two cases) were patients with a floating knee injury; in these situations the use of retrograde nailing of the femur and antegrade to the tibia were preferred.

The group of patients comprised 312 men and 101 women with a mean age of 27.8 years (17-84 years). Patients under the age of 15 were treated in specialised paediatric hospitals. The age distribution is presented in Fig. 1.

Of the fractures, 361 (87\%) were caused by high-energy injuries in traffic accidents. The remaining 54 (13\%) were caused by falls from heights $(9 \%)$, direct impact $(2 \%)$ and other incidents, including gunshots $(2 \%)$.

In accordance with the AO classification the fracture types were: Type A: 105 (25.4\%), Type B: 179 (43.1\%) and Type C: $131(31.5 \%)$ [14]. There were 341 closed fractures and 74 open fractures. Open fractures were further categorised in accordance with the Gustilo classification: 33 fractures were Grade I, 24 Grade II, 14

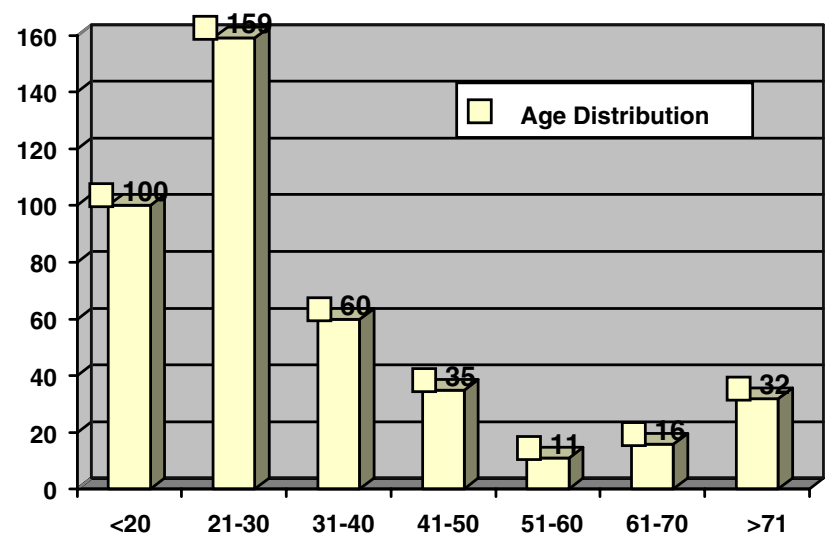

Fig. 1 Age distribution
Grade III A, 2 Grade III B and 1 was Grade III C [15]. Table 1 shows the anatomical sites of the fractures. There were two bilateral fractures, 196 fractures affecting the right side and 215 affecting the left.

There were associated injuries in 116 patients: 28 patients had head injuries, 20 with abdominal injuries, 13 with chest injuries ( 5 with rib fractures, 1 with a sternum fracture and 2 with clavicle fractures) and 55 had other fractures (Table 2). In all cases, the patient's head, abdominal or chest injury was treated prior to the involvement of the orthopaedic team.

The orthopaedic department offers femoral stabilisation in under $12 \mathrm{~h}$ from the injury, and in under $6 \mathrm{~h}$ for open fractures. Those with Grade III-B and III-C fractures were first stabilised with external fixation and intramedullary nailing was performed after 5-7 days. All open fractures were carefully debrided and the wound left open. Only a few retaining stitches, applied without tension, were used to hold the wound together.

The majority of Type A fractures (73) was treated with dynamic intramedullary nailing and Types $\mathrm{B}$ and $\mathrm{C}$ with static nails. In all the reamed technique was used and in 308 of these, the AIM titanium nail (De Puy Orthopaedics) with a mean diameter of $12 \mathrm{~mm}$ inserted. In 107 cases, the Gross-Kempf nail (Stryker) with a mean diameter of $13 \mathrm{~mm}$ was used. In cases of bipolar fractures, a Steinmann pin (closed fractures) was positioned unicortically in order

Table 1 Site of the fracture

\begin{tabular}{lclr}
\hline Location of the fracture & Closed & Open & Total \\
\hline Upper 1/3 & 69 & 10 & 79 \\
Middle 1/3 & 170 & 42 & 212 \\
Lower $1 / 3$ & 102 & 22 & 123 \\
Total & 341 & 74 & 415 \\
\hline
\end{tabular}

Table 2 Other fractures

\begin{tabular}{ll}
\hline Site of the fracture & Number \\
\hline Upper limb & \\
Shoulder & 4 \\
Elbow & 5 \\
Carpal & 7 \\
Spine fractures & 6 \\
Lower limb & \\
Femoral neck & 5 \\
Patella & 6 \\
Tibial plateux & $4(2$ Floating knees) \\
Tibia/ankle & 11 \\
Forefoot & 7 \\
Total & 55 \\
\hline
\end{tabular}


to avoid uncontrolled rotation of the middle segment. Bone reduction forceps were used in cases of open fractures.

The reaming technique was preferred as it enabled insertion of larger nails, thus providing higher fracture stability. The reaming strategy was to measure the canal and ream sequentially until a diameter $1.5 \mathrm{~mm}$ wider than the nail selected was reached. A fracture table was used but the limbs held in traction boots instead of skeletal traction. The distal locking bolts were inserted using a free hand technique; a Kirschner wire was positioned at the locking hole of the nail with X-ray assistance and drilled over with a cannulated drill before insertion of the distal locking screw. A $3-\mathrm{cm}$ distance between the fracture line and the locking screw was considered a safe distance. Lateral $\mathrm{X}$-rays were also used in an attempt to avoid procurvatum or recurvatum deformities in fracture alignment.

Prior to the introduction of the proximal locking screw and after release of traction, two steps were performed that were considered to be critical to the outcome: (a) the two legs were aligned parallel in order to check length and avoid any discrepancy (we ensured that the traction boots and patellae were at the same level) and, (b) the patella was marked with a sterile pen and its position was used to check for any possible malrotation of the distal part of the fracture. In cases of malrotation, the nail and the distal part of the fracture were rotated and placed in the correct position. After checking with an X-ray of the fracture site, the proximal locking screw was inserted.

Data obtained from case notes indicated a mean operating time (surgery only) was 50 minutes (20-80), and mean radiation exposure was 18 seconds (5-42). Mean blood loss for all fractures was $500 \mathrm{cc}(200-1,600)$ and post-operative blood transfusion necessary in all patients with haematocrit of $<29 \%$.

Prophylactic antibiotics (a second generation cephalosporin) were used for $48 \mathrm{~h}$ post-operatively and lowmolecular weight heparin for 30 days. Prior to discharge, patients received instruction in self-administration of lowmolecular weight heparin; in selected cases, visiting nurses administered these injections. The open fractures had extended intravenous antibiotic treatment for a mean period of 7 days, followed by oral administration for a period of at least 7 days depending on the tissue damage.

From the second post-operative day, all patients were encouraged to walk partial weight bearing with the exception of patients with type $\mathrm{C}$ fractures, who started weight bearing after the fourth week, and those with other ipsilateral lower limb fractures. Follow-up was in the first month and repeated in the third, sixth and twelfth months. At the last follow-up, range of motion was measured and compared with the uninjured leg.

Statistical analysis of the data was performed using the Statistical Package for the Social Sciences (SPSS), version
11.0 (SPSS, Inc., Chicago, IL, USA). The chi-square test was used to evaluate any potential association of complication rates with the type of fractures. Odd ratios (OR) and $95 \%$ confidence intervals (CI) were estimated, by means of simple logistic regression analysis, as the measure of association between complications and the type of fractures. All tests were two-tailed, and statistical significance was considered for $P$ values $<0.05$.

\section{Results}

Mean hospitalisation was 8 days (6-15). After a mean follow-up of 1.5 years (1-3), 404 fractures were united $(97.8 \%$; Figs. 2, 3). Healing was defined as the circumferential presence of bridging callus, confirmed by means of anteriorposterior and lateral radiographs and the absence of pain on palpation or during weight bearing. Type A fractures united in an average time of 16 weeks (13-18), Type B in 20 weeks (16-22) and Type $\mathrm{C}$ in 23 weeks (19-27).

Two patients (aged 77 and 81) failed to attend appointments after 1 year. The complications with respective statistical analyses are presented in Table 3. In detail, they were as follows:

Intraoperative:

1. One nail bent during insertion.

2. There was breakage of the Kirschner wire in ten cases and, in three other cases, the cannulated drill broke.

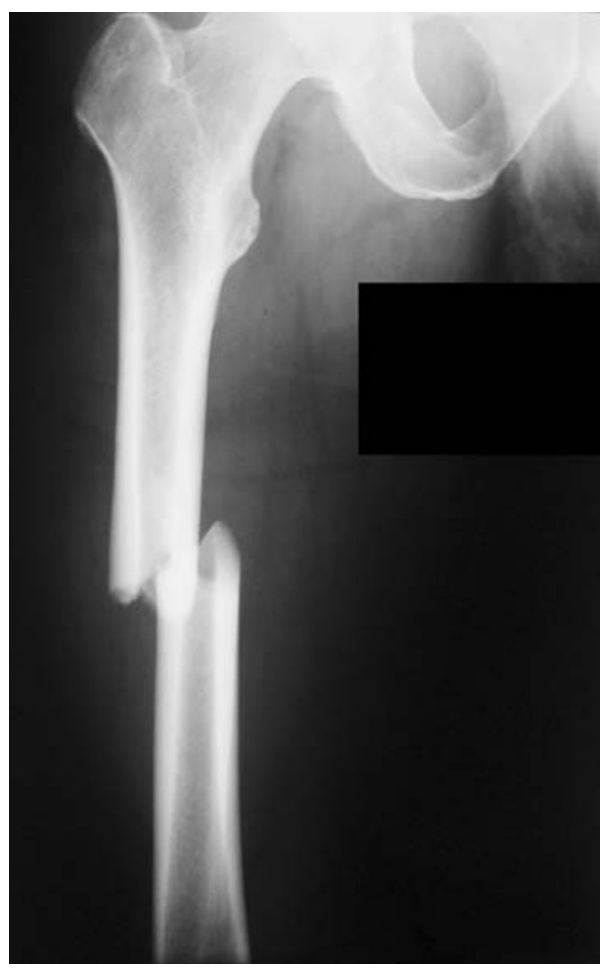

Fig. 2 A type A fracture 

static intramedullary nailing technique
Fig. 3 The fracture treated with

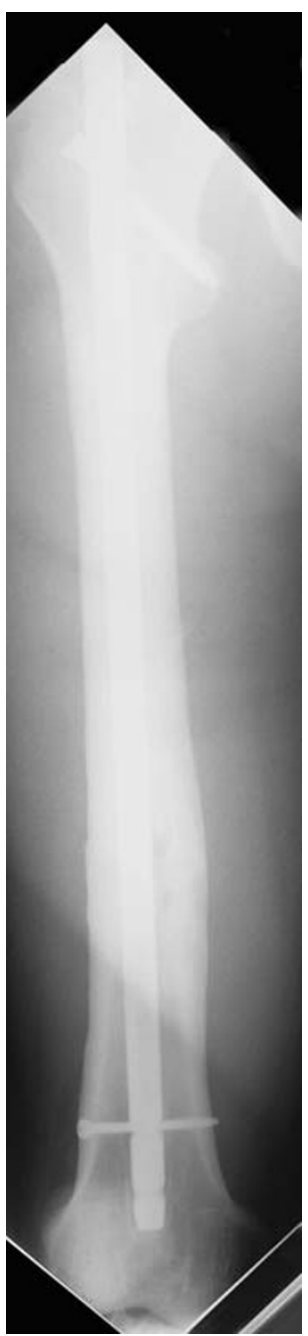

\section{Post-operative:}

1. A non-union, defined by the absence of union after 6 months, occurred in 9 cases (2.2\%), and were categorised as follows: Type A-1, Type B-3 and Type C-5. All healed following exchange nailing. In two cases of atrophic non-union, bone graft from the iliac crest was used (aseptic pseudoarthrosis, depicted in Fig. 4).

2. A delayed union, defined as the absence of progress to union after 3 months, occurred in 14 cases (3.4\%), and were categorised as follows: Type B-10, Type C-4 (Fig. 5). In ten cases, dynamisation of the fracture was performed following removal of the distal bolts under local anaesthesia. The remaining four fractures joined without further treatment.

3. Torsional malunion of greater than $5^{\circ}$ occurred in 4 cases $(0.96 \%)$ and were divided as follows: Type B-3, Type C-1. All were treated by osteotomy and exchange nailing. One required internal rotation, and three required external rotation corrections.
4. Limb shortening of greater than $15 \mathrm{~mm}$ occurred in 6 cases (1.44\%) and were from Type B (1) and Type C (5) fractures. In four cases, the proximal screw could not be centralised due to a failure of the device (Fig. 6). The screw was revised and positioned correctly, using a closed technique on the second post-operative day. In one case, the severity of the fracture and the weight of the patient were not fully appreciated; the distal locking screw broke in the course of the second month. It was decided to revise both the nail and the locking screws for this case. The last case was a comminuted fracture where, despite limb shortening diagnosed early, it was decided an osteotomy be performed and lengthening external fixation device used after extracting the nail. The patient contracted pin site infections during the last month of lengthening, but the fracture/osteotomy healed without further complications.

5. One deep infection occurred in a type III $\mathrm{C}$ open fracture and one superficial wound infection in a diabetic patient (type III A). Both were treated with antibiotics and daily local irrigation. The deep infection was diagnosed early following a culture of the drain tip used after surgery and, as a result, the implant was not removed after debridement and replacement of the proximal locking screw.

6. There were five (1.2\%) pulmonary embolic events: three thrombus related $(0.7 \%, 2$ in type $\mathrm{B}$ and 1 in type C) and two fat $(0.5 \%, 1$ in each of type B and C fracture groups). Only one of these patients had a chest injury $(0.08 \%)$. None of the embolisms were lethal nor left any residual symptoms. In four patients, deep vein thrombosis (DVT) below the knee was recorded. This was treated conservatively with an appropriate adjustment of the low-molecular weight heparin dosage.

7. A nerve palsy occurred in 30 patients (7.2\%, Table 3$)$. Twenty-five pareses of the pudendal nerve (6\%), and five $(1.2 \%)$ of the peroneal nerve were observed, with all attributable to traction. All recovered within 3 months. More than $50 \%$ of the pareses occurred during the learning curve (first 3 years of this study).

8. There were implant failures. Twenty-eight broken screws were found but no broken nails (Fig. 7). The majority of these were observed during the first part of the study where cannulated screws were used.

9. In 29 patients $(6.9 \%)$, pain over the distal screws occurred, from local irritation of the iliotibial tract, 2-3 months after the intervention. In these cases the screws were removed. In 27 patients $(6.5 \%)$ the nail was removed at the end of the treatment due to hip, thigh or knee pain. Three patients reported hip pain because of nail protrusion from the piriformis fossa greater than $1 \mathrm{~cm}$. 
Table 3 Complications in details and statistical significance

\begin{tabular}{|c|c|c|c|c|c|}
\hline Type of complications & $\begin{array}{l}\text { Total number of } \\
\text { complications }\end{array}$ & $\begin{array}{l}\text { AO type A } \\
(n=105)\end{array}$ & $\begin{array}{l}\text { AO type B } \\
(n=179)\end{array}$ & $\begin{array}{l}\text { AO type C } \\
(n=131)\end{array}$ & $P$ value \\
\hline Intraoperative & $14(3.3 \%)$ & $1(1.0)$ & $8(4.5)$ & $5(3.8)$ & 0.269 \\
\hline Nail bend & $1(0.2 \%)$ & $1(1.0)$ & - & - & 0.228 \\
\hline Broken K-wires & $10(2.4 \%)$ & - & $6(3.4)$ & $4(3.1)$ & 0.174 \\
\hline Broken cannulate drills & $3(0.72 \%)$ & - & $2(1.1)$ & $1(0.8)$ & 0.561 \\
\hline Severe post-operative complications & $70(16.9 \%)$ & $6(6.7)$ & $32(17.9)$ & $31(23.7)$ & 0.002 \\
\hline Non-union $>6$ months & $9(2.2 \%)$ & $1(1.0)$ & $3(1.7)$ & $5(3.8)$ & 0.271 \\
\hline Delayed union $>3$ months & $14(3.4 \%)$ & & $10(5.6)$ & $4(3.1)$ & 0.180 \\
\hline Torsional malunion $>5^{\circ}$ & $4(0.96 \%)$ & - & $3(1.7)$ & $1(0.8)$ & 0.363 \\
\hline Limb shortening $>15 \mathrm{~mm}$ : & $6(1.44 \%)$ & - & $1(0.6)$ & $5(3.8)$ & 0.021 \\
\hline \multirow[t]{2}{*}{ Infection: $2(0.48 \%)$} & 1 Deep $(0.2 \%)$ & - & - & $1(0.8)$ & 0.337 \\
\hline & 1 Superficial $(0.2 \%)$ & - & - & $1(0.8)$ & 0.337 \\
\hline \multirow[t]{2}{*}{ Embolism: 5 (1.2\%) } & 3 Pulmonary $(0.7 \%)$ & - & $2(1.1)$ & $1(0.8)$ & 0.561 \\
\hline & $2(0.5 \%)$ Fat & - & $1(0.6)$ & $1(0.6)$ & 0.688 \\
\hline \multirow[t]{2}{*}{ Nerve palsy in 30 patients $(7.2 \%)$} & 25 Pareses of the pudendal nerve $(6 \%)$ & $5(4.8)$ & $11(6.1)$ & $9(6.9)$ & 0.792 \\
\hline & $5(1.2 \%)$ Of the peroneal nerve & - & $2(1.1)$ & $3(2.3)$ & 0.274 \\
\hline Less severe post-operative complications & $60(14.45 \%)$ & $12(11.4)$ & $29(16.2)$ & $19(14.5)$ & 0.544 \\
\hline \multirow[t]{2}{*}{ Pain: $32(7.7 \%)$} & 29 Iliotibial band (6.9\%) & $5(4.8)$ & $15(8.4)$ & $9(6.9)$ & 0.513 \\
\hline & 3 Hip pain $(0.72 \%)$ & $1(1.0)$ & $2(1.1)$ & - & 0.492 \\
\hline Implant failure & 28 Broken screws $(6.75 \%)$ & $6(5.7)$ & $12(6.7)$ & $10(7.6)$ & 0.843 \\
\hline Total number of complications & & 19 (19.0) & $70(38.5)$ & $55(42.0)$ & $<0.001$ \\
\hline
\end{tabular}

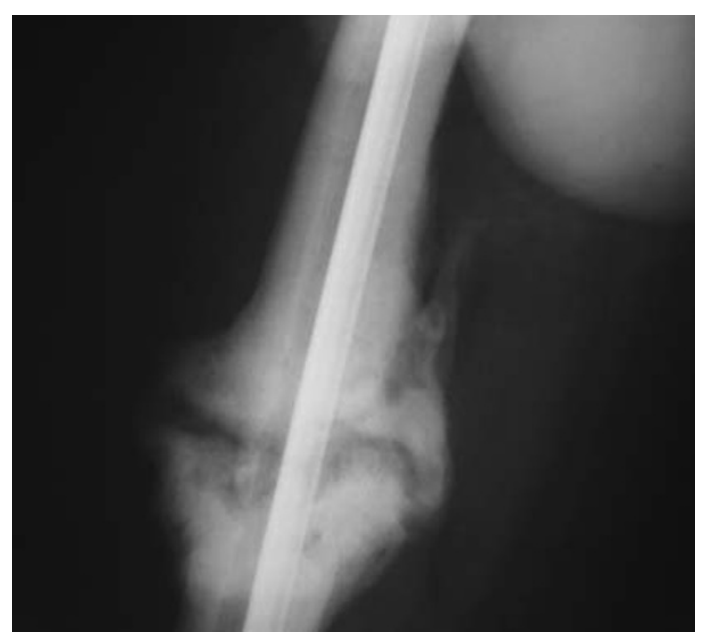

Fig. 4 Non-union

The complications in the three groups of patients are shown in Table 3. The incidence of intraoperative and minor post-operative complications was higher in type B and $\mathrm{C}$ fractures compared to type $\mathrm{A}$, but was not statistically significant. The overall severe post-operative complication rates were statistically significantly higher in type $\mathrm{B}$ and $\mathrm{C}$ fractures compared to type A (17.9 and 23.7 vs. $6.7 \%, P=0.002)$; in this regards, logistic regression analysis revealed that type $\mathrm{B}$ and $\mathrm{C}$ were associated with increased risk of complications, with respective odds ratios

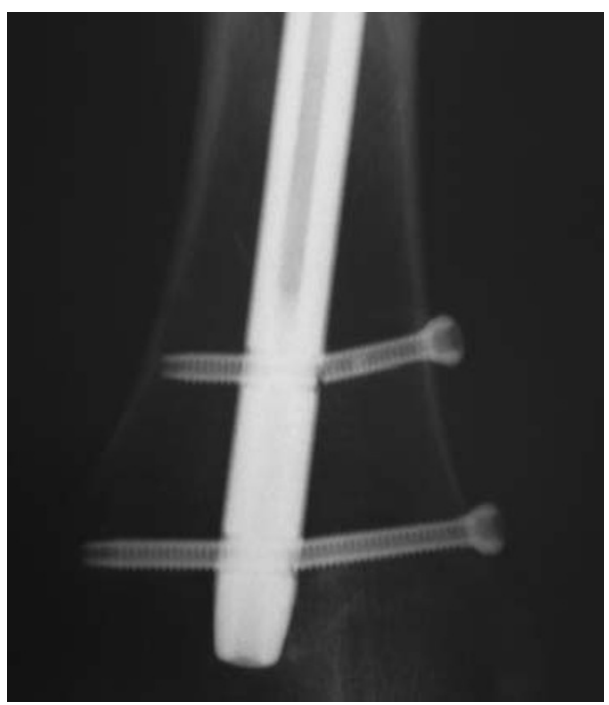

Fig. 5 Delayed union

of $3.1(95 \% \mathrm{CI}=1.3-7.2, P=0.011)$ and $4.3(95 \%$ $\mathrm{CI}=1.8-10.3, P=0.001)$ compared to type A.

At the end of the follow-up period, none of the patients needed crutches. The mean range of knee motion was $122^{\circ}$ flexion and $3^{\circ}$ extension. Post-operative measurements are grouped according to AO fracture type as in Table 4. According to data collected, Type $\mathrm{C}$ fractures have a 


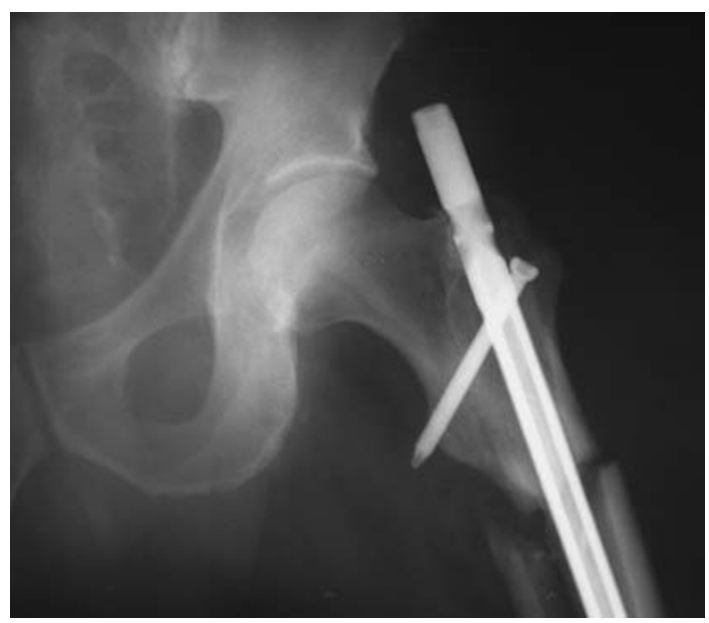

Fig. 6 Limb shortening/failed proximal locking screw

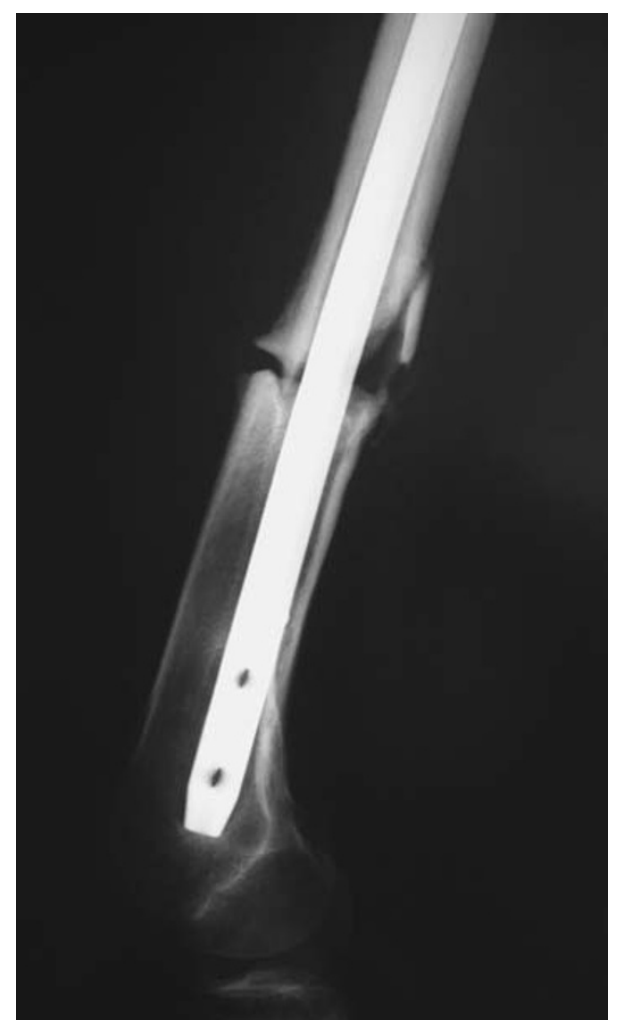

Fig. 7 Broken screws. In this case, the screws were of a cannulated type

smaller mean range of movement when compared with the other two types. There was a relation between a reduced range of motion and a history of patella and/or tibial plateau fracture, probably due to the necessity for open reduction and fixation of these fractures. Our study could not confirm any relation between decreased range of motion and the presence of an open fracture; this may be due to the small numbers of severe open fractures (3 IIIB and 1 IIIC). In addition, the guidelines followed for severe open fractures
Table 4 The range of motion in relation to the AO fracture pattern (mean values)

\begin{tabular}{lll}
\hline Fracture type according AO & Flexion $\left(^{\circ}\right)$ & Extension $\left(^{\circ}\right)$ \\
\hline Type A & 127 & 1 \\
Type B & 120 & 3 \\
Type C & 115 & 7 \\
All fractures & 122 & 3 \\
\hline
\end{tabular}

Those data were not provided in all fractures and there was not performed an inter-observer liability test

include temporary initial external fixation followed by secondary definitive intramedullary nailing [16].

Of the 415 nails inserted, only 52 were removed (27 due to pain) after union regardless of all the patients having been advised to have the nails removed at the conclusion of therapy. Another 124 refused or postponed hardware removal. In this retrospective study, the patients returned to their previous activities in a mean of 10 months [7-18].

\section{Discussion}

The experience gained with interlocking nails has led to the decision to treat nearly all femoral shaft fractures with this technique which provides good bone stability with limited soft tissue exposure and dissection. Use of intramedullary nails for acute treatment of Gustilo IIIB and IIIC fractures was avoided. The advantages of this technique are considerable: reduced risk of infection, blood loss, and morbidity. In comparison with methods of internal fixation, patient mobilisation is earlier and hospitalisation time shorter, thus reducing treatment costs [11, 17-21]. Trochanteric-entry point nails and retrograde nailing are also valid options in the treatment of femoral shaft fractures but whether this technique produces results comparable to those of antegrade femoral nails remains to be established [4, 22-25].

The use of reamed (RN) or unreamed (URN) intramedullary nailing remains controversial, especially in relation to open fractures. Reamed intramedullary nailing provides better stability because of increased contact between the nail and medullary canal. Larger nails can be used in order to lessen failure due to fatigue. Reaming is also believed to increase operative time, blood loss, fracture comminution and create a ramping effect. On the other hand, unreamed nails are usually simpler to use and can be inserted more quickly, but their smaller diameter provides less rigid fixation. The literature seems to indicate that the advantages (high union rate, less revisions, fewer nonunions) of the reamed nails are more important than the disadvantages (prolonged surgical time, blood loss) [9, 12, $13,26]$. The authors believe that despite the unquestionable 
advantages of the reaming technique, unreamed nails could be used in selected cases that take into consideration the patient's health status and the surgeon's capabilities.

Several investigators have attempted to demonstrate a relationship between reamed intramedullary nailing, fat embolism and Adult Respiratory Distress Syndrome (ARDS). Blitzer and Hamilton [27] have shown there is significant embolisation of the bone marrow contents to the heart and lung with reaming and pressurisation of the femoral intramedullary canal. These findings were compounded in another study which demonstrated that these conditions could in turn increase the incidence of ARDS in multitrauma patients, especially those with pulmonary injuries [28]. However, by the late 1990s, opinions had changed. There were reports of no difference in the incidence of ARDS in patients treated with intramedullary nailing or plate fixation, regardless of treatment occurring within the first $24 \mathrm{~h}$ [29-31]. These authors found that nailing was not related to increased mortality or morbidity in patients with femoral fractures and concomitant thoracic injuries. In a review, Giannoudis et al. [32] reported that the systemic response following intramedullary nailing included the effect of embolised fat on lung tissue and an inflammatory reaction depending on polymorphism of neutrophil receptors. They believed that the effect of embolism is related to an individual patient's response, which in turn depends on several cofactors (lung contusion, traumatic shock, preexisting lung disease, sepsis, tissue damage, increased coagulation and altered cell cytoskeleton).

From the outset, we supported the idea of early intramedullary nailing for femoral shaft fractures. In our series, $97 \%$ of the patients were treated with reamed femoral nails in the first $24 \mathrm{~h} \mathrm{[33].} \mathrm{The} \mathrm{use} \mathrm{of} \mathrm{titanium} \mathrm{nails} \mathrm{was} \mathrm{pre-}$ ferred, from the modulus of elasticity being closer to bone and, fatigue, yield and tensile strength higher than other implants.

Table 5 presents the complications in this study and compares them with other published reports. The nonunion rate noticed in the present study (2.2\%) is in close agreement with the majority of the data presented in previous papers [5, 10, 17, 34, 35]. Winquist and Hansen [19], Lambiris et al. [36] and Wolinsky et al. [37] presented non-union rates lower than ours $(0.9,0.31$ and $1.1 \%$ respectively), but other studies $[6,34,37,38]$ have been published with higher rates. In particular, Noumi et al. [11] reported a $14.1 \%$ of non-union rate in a case series of 89 open fractures.

In our series, torsional malunion in excess of $5^{\circ}$ was observed in four cases and limb shortening in excess of $15 \mathrm{~mm}$ was observed in six cases; in total, 10 cases $(2.4 \%)$. Such a percentage is lower than in other published series in which the incidence varied from 4 to $21.1 \%[6,19,34,37]$. These results could be explained by use of first generation nails in the earlier series. With newer designs, Kempf et al. [6] decreased their malunion rate to $11.2 \%$. Our results are in agreement with Gonschorek's [17] but there are studies with even lower malunion rates $[10,38,39]$. A possible explanation to the wide variation is measurement error. Brumback et al. [40] showed a $10 \%$ marginal error in the surgeon's ability to determine axial and rotational stability from preoperative X-rays and intraoperative fluoroscopy.

The incidence of infection for closed fractures is generally less than $1 \%$ and in open fractures $2-5 \%$ [39]. The incidence in this series was $0.5 \%$, similar to some, and lower in comparison with other reports [4, 19, 34, 36, 37]. Notable are reports by Noumi et al. which had $5.6 \%$ in his series of open fractures and Yokoyama et al. with $6 \%$ $[11,21]$. On the other hand, there were no infections reported by Wiss et al., Giannoundis et al., Im et al. and Ricci et al. [5, 10, 22, 38].

Another complication was neurological palsy due to excessive traction. Of the 413 patients treated, 30 patients had evidence of nerve palsy (7.2\%); 25 had paresis of the pudendal nerve and 5 of the peroneal nerve. All recovered within 3 months. There are few reports of neuro-complications in other series of treated femoral shaft fractures. Soem have reported a higher incidence (9.4 and 15\%), but others where the percentage varied from 1 to $3 \%$ [38, 40-43]. Owing to this high incidence, we routinely inform patients of this possibility prior to surgery and apply the minimum of traction necessary for the reduction of the fracture.

Four cases of DVT are reported in this series $(0.96 \%)$, which is small compared to the $2.2 \%$ of Umer et al. [43] Five pulmonary embolisms were encountered, three $(0.7 \%)$ thrombus-related and two $(0.5 \%)$ fat; only one of these patients had a chest injury $(0.08 \%)$. Some authors report a lung complication rate of $14.6 \%$ in femoral fractures but suggest further study is needed [44]. Additionally, a number of co-factors may be responsible for the effect that fat has on the lungs [32].

Nail failure has been reported by Gonschorek et al. and Wolinsky et al. [17, 37], but the majority of studies report failures of the locking bolts. Twenty-eight distal locking bolt breakages were experienced, the majority of them during the first part of the study [45]. This led to discontinuation of the use of cannulated locking bolts and a policy to insert both bolts in all static nailing procedures. In addition, in severely comminuted fractures and overweight patients, the weight bearing protocol was altered.

Thigh pain, trochanteric pain, limb shrinkage and difficulties with stair climbing are often reported especially during the first 6 months post-operatively. In recent studies, authors have reported persistent hip or knee pain following intramedullary nailing [34, 36, 38, 43]. In some cases, the pain was so intense that the implant had to be removed at the end of the treatment. In the present study, 
Table 5 Published series and the complications presented

\begin{tabular}{|c|c|c|c|c|c|c|c|c|}
\hline \multirow[t]{2}{*}{ Authors } & \multirow{2}{*}{$\begin{array}{l}\text { Number of } \\
\text { fractures }\end{array}$} & \multicolumn{7}{|c|}{ Complications in $\%$} \\
\hline & & $\begin{array}{l}\text { Malunion } \\
\text { torsion/ } \\
\text { shortening }\end{array}$ & $\begin{array}{l}\text { Non- } \\
\text { union }\end{array}$ & Infection & $\begin{array}{l}\text { Nerve } \\
\text { palsy }\end{array}$ & Embolism & $\begin{array}{l}\text { Implant } \\
\text { failure }\end{array}$ & $\begin{array}{l}\text { Other } \\
\text { comments }\end{array}$ \\
\hline Winquist et al. [20] & 520 & 4.2 & 0.9 & 0.9 & & & & \\
\hline Kempf et al. [6] & 52 & 21.1 & 7.6 & 2.1 & & & & \\
\hline Wiss et al. [5] & 112 & 14 & 1.8 & 0 & & & & \\
\hline Kempf et al. [35] & 385 & 11.2 & 1.3 & 2.1 & & & & \\
\hline Giannoudis et al. [10] & 147 & 0 & 1.3 & 0 & & & & \\
\hline Lambiris et al. [36] & 770 Multicenter & - & 0.31 & 0.7 & & & & \\
\hline Gonschorek et al. [17] & 179 & 2.6 & 1.3 & 1.3 & & & 1.3/Nail & \\
\hline Wolinsky et al. [37] & 551 & 12 & 1.1 & 1.1 & & & One nail/13 bolts & \\
\hline Larsen et al. [42] & 90 Acute fracture & 4.4 & 4.4 & 2.2 & 2.2 & & & $82 \%$ No pain \\
\hline $\begin{array}{l}\text { Theodoratos } \\
\text { et al. [45] }\end{array}$ & 313 Acute fracture & 2.2 & 1.6 & 0 & 8.3 & 0.96 & 23 Bolts & 2 DVT \\
\hline Im et al. [38] & 99 Acute fracture & 1 & 1 & 0 & 1 & & 8 Bolts & $\begin{array}{l}12 \% \text { Delayed union } \\
\text { No pain }\end{array}$ \\
\hline Harris et al. [34] & 101 & $\begin{array}{l}\text { Malunion } \\
\text { and non- } \\
\text { union = } 23\end{array}$ & & & & & & $\begin{array}{l}4 \text { Heterotopic } \\
\text { ossification } \\
\text { 18/35 Hip pain }\end{array}$ \\
\hline Umer et al. [43] & 89 Acute fracture & 4 & 4.4 & 4 & 3 & & & $\begin{array}{l}2 \text { DVT } \\
4 \% \text { Pain }\end{array}$ \\
\hline Noumi et al. [11] & 89 Open fracture & & 14.1 & 5.6 & & & & \\
\hline Ricci et al. [22] & 61 & 0 & 1.64 & 0 & & & & $\begin{array}{l}\text { Trochanteric nails } \\
\text { 13.1 Pain }\end{array}$ \\
\hline Present study & 415 Acute fracture & 2.4 & 2.2 & 0.5 & 7.2 & 1.2 & 28 Bolts & $\begin{array}{l}\text { 4DVT } 13.5 \% \text { pain } \\
3.4 \text { Delayed union }\end{array}$ \\
\hline
\end{tabular}

27 nails $(6.5 \%)$ were removed due to pain after fracture consolidation. Twenty-nine patients $(6.9 \%)$ reported local pain with the distal screws. In these selected cases, the screws were removed after the third month and the problem resolved.

\section{Limitations of the study}

The study is retrospective; incomplete data sets were difficult to reconcile. Data for measurement of angular alignment was available only in complicated cases. In addition data for torsional malunion, limb shortening and range of motion were not controlled with indicators of the inter-observer variation.

\section{Conclusion}

In this study, the efficacy of the antegrade intramedullary nailing as a preferred treatment for closed and open femoral shaft fractures is presented. The treatment of severe comminuted and open fractures (Gustilo III A, B, C) requires extra attention. Logistic regression analysis revealed that $\mathrm{AO}$ type $\mathrm{B}$ and $\mathrm{C}$ fractures were associated with increased risk of complications, with respective odds ratios of 3.1 (95\% CI $=1.3-7.2, P=0.011)$ and $4.3(95 \% \mathrm{CI}=1.8$ $10.3, P=0.001)$ when compared to type A. Early fracture reduction and intramedullary nailing, early mobilisation and weight bearing are the critical points and are related to the good outcome in this series. The newer generation nails continue to maintain the high union rates reported initially with the technique. The complications observed are attributable not only to the individuality of the fracture and patient, but also to the individual surgeons' capabilities.

Acknowledgments The study was self-supported for our hospital, the Hellenic Red Cross Hospital of Athens.

\section{References}

1. Küntscher G (1940) Die Marknagelung von Knochenbrüchen. Arc Klin Chir 200:435-455

2. Küntscher G (1958) The Küntscher method of intramedullary fixation. J Bone Joint Surg [Am] 40:17-26 
3. Kempf I, Jaefer JH, North J et al (1976) L'enclouage centromedullaire de femur et du tibia selon la technique de Küntscher. Intérêt du verrouillage du clou. Acta Orth Belgica 42:29-43

4. Kempf I, Grosse A, Lafforgue L (1978) Combined Kuntscher nailing and screw fixation. Rev Chir Orthop Reparatrice Appar Mot 64:635-651

5. Wiss DA, Fleming CA, Matta JM, Clark D (1986) Comminuted and rotationally unstable fractures of the femur treated with an interlocking nail. Clin Orthop 212:35-47

6. Kempf I, Grosse A, Beck G (1985) Closed locked intramedullary nailing. Its application to comminuted fractures of the femur. J Bone Joint Surg [Am] 67:709-720

7. Klemm KW, Borner M (1986) Interlocked nailing of complex fractures of the femur or the tibia. Clin Orth 212:89-100

8. Thorensen BO, Alho A, Ekel A et al (1985) Interlocking intramedullary nailing in femoral shaft fractures: a report of forty-eight cases. J Bone Joint Surg [Am] 67:1313

9. Forster MC, Aster AS, Ahmed S (2005) Reaming during anterograde femoral nailing: is it worth it? Injury 36:445-449

10. Giannoudis PV, Furlong AJ, MacDonald DA, Smith RM (1997) Reamed against unreamed nailing of the femoral diaphysis: a retrospective study of healingtime. Injury 28:15-18

11. Noumi T, Yokoyama K, Ohtsuka H et al (2005) Intramedullary nailing for open fractures of the femoral shaft: evaluation of contributing factors on deep infection and nonunion using multivariate analysis. Injury 36(9):1085-1093

12. Tornetta P, Tiburzi D (2000) Reamed versus nonreamed anterograde femoral nailing. J Orthop Trauma 14:15-19

13. Shepherd LE, Shean CJ, Gelalis ID et al (2001) Prospective randomized study of reamed versus unreamed femoral intramedullary nailing: an assessment of procedures. J Orthop Trauma 15(1):28-32

14. Muller ME (1980) Classification and international AO-documentation of femur fractures. Unfallheilkunde 83(5):251-259

15. Gustilo RB, Anderson JT (1976) Prevention of infection in the treatment of one thousand and twenty-five open fractures of long bones: retrospective and prospective analyses. J Bone Joint Surg Am 58(4):453-458; 84-A(4):682

16. Scalea TM, Boswell SA, Scott JD et al (2000) External fixation as a bridge to intramedullary nailing for patients with multiple injuries and with femur fractures: damage control orthopaedics. J Trauma 48:613-623

17. Gonschorek O, Hofmann GO, Buhren V (1998) Interlocking compression nailing: a report on 402 applications. Arch Orthop Trauma Surg 117(8):430-437

18. Whittaker APW, Heppenstall B, Menkowitz E, Montique F (1982) Comparison of open vs closed rodding femurs utilizing a Sampson rod. J Trauma 22:461

19. Winquist RA, Hansen ST (1980) Comminuted fractures of the femoral shaft treated by intramedullary nailing. Orthop Clin North Am 11:633

20. Winquist RA, Hansen ST, Clawson DK (1984) Closed I. N. of femoral fractures. J Bone Joint Surg (Am) 66(4):529-539

21. Yokoyama K, Itoman M, Shindo M et al (1999) Deep infection and fracture healing in immediate and delayed locked intramedullary nailing for open femoral fractures. Orthopedics 22(5):485490

22. Ricci WM, Devinney S, Haidukewych G et al (2005) Trochanteric nail insertion for the treatment of femoral shaft fractures. J Orthop Trauma 19(8):511-517

23. Anup K, Mehra MM (2002) Retrograde femoral interlocking nail in complex fractures. J Orthop Surg (Hong Kong) 10(1):17-21

24. Papadokostakis G, Papakostidis C, Dimitriou R (2005) The role and efficacy of retrograding nailing for the treatment of diaphyseal and distal femoral fractures: a systematic review of the literature. Injury 36(7):813-822
25. Ricci WM, Bellabarba C, Evanoff B et al (2001) Retrograde versus antegrade nailing of femoral shaft fractures. J Orthop Trauma 15(3): 161

26. Orler R, Locher S, Lottenbach M et al (2002) Retrospective analysis of healing problems after reamed and unreamed nailing of femoral shaft fractures. Unfallchirurg 105(5):431-436

27. Blitzer CM, Hamilton L (1992) Oxygen saturation during reaming and intramedullary nailing of the femur. Orthopedics 15:1403-1405

28. Pape HC, Auf'm Kolk M, Paffarath T et al (1993) Primary intramedullary femur fixation in multitrauma patients with associated lung contusion: a cause of post traumatic ARDS. J Trauma 34:540-548

29. Bosse MJ, MacKenze EJ, Riemer BL et al (1997) Adult respiratory distress syndrome, pneumonia, and mortality following thoracic injury and a femoral fracture treated either with intramedullary nailing with reaming or with a plate. A comparative study. J Bone Joint Surg Am 79(6):799-809

30. Brundage SI, McGhan R, Jurkovich GJ et al (2002) Timing of femur fracture fixation: effect on outcome in patients with thoracic and head injuries. J Trauma 52:299-307

31. Handolin L, Pajarinen J, Lassus J et al (2004) Early intramedullary nailing of lower extremity fracture and respiratory function in polytraumatized patients with a chest injury: a retrospective study of 61 patients. Acta Orthop Scand 75(4):477-480

32. Giannoudis PV, Pape HC, Cohen AP et al (2002) Review systemic effects of femoral nailing. Clin Orth Relat Res 404:378-386

33. Wood GW II (ed) (2003) Mosby Campbell's operative orthopaedics, 10th edn, vol III, Chap. 50. General principles of fracture treatment, pp 2269-2723

34. Harris I, Hatfield A, Donald G et al (2003) Outcome after intramedullary nailing of femoral shaft fractures. ANZ J Surg 73(6):387-389

35. Kempf I, Grosse A, Taglang G et al (1991) Interlocking central medullary nailing of recent femoral and tibial fractures. Statistical study apropos of 835 cases. Chirurgie 117:478-487

36. Lambiris E, Zouboulis P, Karioris G et al (1997) Multicenter study for the intramedullary nailing in Greece. Acta Orthopaedica Hellenica 48:128-137

37. Wolinsky PR, McCarty E, Shyr Y et al (1999) Reamed intramedullary nailing of the femur: 551 cases. J Trauma 46:392-399

38. Im G, Shin SR (2002) Treatment of femoral shaft fractures with a titanium intramedullary nail. Clin Orthop Relat Res (401):223 229

39. Whittle AP, Wood GW II (ed) (2003) Mosby Campbell's operative orthopaedics, 10th edn, vol III, Chap. 51. Fractures of the lower extremity, pp 2725-2872

40. Brumback RJ, Ellison TS, Molligan H et al (1992) Pudendal nerve palsy complicating intramedullary nailing of the femur. J Bone Joint Surg [Am] 4:1450

41. Kao JT, Burton D, Cornstock C et al (1993) Pudendal nerve palsy after femoral intramedullary nailing. J Orthop Trauma 7:58

42. Larsen SE, Nielsen KS, Larsen MS et al (2000) Treatment of femoral shaft fractures with Grosse-Kempf intramedullary nail. J Orthop Sci 5(4):328-332

43. Umer M, Niazi AK, Hussain D et al (2004) Treatment of acute fractures of the femoral shaft with reamed intramedullary interlocking AO nails. J Pak Med Assoc 54(8):423-427

44. Anwar IA, Battistella FD, Neiman R et al (2004) Femur fractures and lung complications: a prospective randomized study of reaming. Clin Orthop Relat Res (422):71-76

45. Theodoratos G, Karadimas EJ, Petroutsas J et al (2003) The treatment of the femoral diaphyseal fracture with intramedullary nailing: a review of 313 cases. Osteo Trauma Care 11:81-84. http://www.thieme-connect.de/ejournals/html/osteotrauma/doi/10. 1055/-A123-1 